\title{
Oceanic Fluxes in the South Atlantic
}

\author{
Elaine L. McDonagh And Brian A. King \\ Southampton Oceanography Centre, Empress Dock, Southampton, United Kingdom
}

(Manuscript received 30 December 2002, in final form 23 June 2004)

\begin{abstract}
A box inverse of the World Ocean Circulation Experiment A10 (30 $\mathrm{S}$ ) and A11 (nominally $45^{\circ} \mathrm{S}$ ) sections in the South Atlantic Ocean was undertaken. The authors find a heat flux across A10 of $0.22 \pm 0.08$ PW, consistent with previous studies, and a heat flux of $0.43 \pm 0.08 \mathrm{PW}$ across A11. The A11 heat flux is lower than some previous analyses of this section but implies a plausible oceanic heat convergence (heat loss to the atmosphere) of $0.21 \pm 0.10 \mathrm{PW}$. The difference is principally due to adding a cyclonic component to the circulation in the Cape Basin. As compared with the solution of other studies, the anticyclonic circulation in the surface and intermediate water of the subtropical gyre is weakened. The circulation of the deep water is cyclonic rather than anticyclonic; this is in better agreement with previously published circulation schemes based on examination of water properties. A southward freshwater flux of $0.7 \mathrm{~Sv}\left(1 \mathrm{~Sv} \equiv 10^{6} \mathrm{~m}^{3} \mathrm{~s}^{-1}\right)$ at $\mathrm{A} 11$, consistent with previous inverse studies, is still inconsistent with the net Atlantic evaporation inferred from integrated surface climatologies. Results suggest a small gain of freshwater $(0.2 \pm 0.1 \mathrm{~Sv})$ between the sections.
\end{abstract}

\section{Introduction}

The overturning circulation in the South Atlantic consists of surface and intermediate waters traveling northward above North Atlantic Deep Water (NADW) flowing southward; below that is found bottom water that formed in the Antarctic, also flowing northward. The surface and intermediate waters ultimately feed the production of NADW in the northern limb of the overturning. Determining the strength of this overturning circulation gives us insight into the elements that contribute to the thermohaline circulation, as well as allowing diagnosis of the net contribution of the ocean to heat, freshwater, and nutrient fluxes in the South Atlantic.

During the World Ocean Circulation Experiment (WOCE), 10 coast-to-coast quasi-zonal sections were occupied in the Atlantic. These were designed to measure the meridional fluxes of properties such as heat. The two southernmost of these, designated A10 $\left(30^{\circ} \mathrm{S}\right)$ and A11 (nominally $45^{\circ}$ S, Fig. 1), were occupied nearly simultaneously between 27 December 1992 and 31 January 1993.

We use box inverse methods (Wunsch 1996) to produce a circulation with consistent fluxes of mass, heat,

Corresponding author address: Elaine L. McDonagh, Southampton Oceanography Centre, Empress Dock, Southampton, Hampshire SO14 3ZH, United Kingdom.

E-mail: elm@soc.soton.ac.uk salt, and silicate through the A10 and A11 sections. Although the sections were occupied nearly simultaneously, we do not intend to produce a circulation scheme that represents the ocean state in that month. Rather, we intend our solution to represent the mean circulation. To this end we invoke the arguments made by Bryden and Imawaki (2001) that the density field is slowly varying and represents the mean circulation over some time scale if average boundary currents and Ekman fluxes are used. An advantage of using such a regional inverse with only two sections is that it is feasible to make a careful study of detailed aspects of the flow across each section. As well as the careful consideration of boundary currents crucial to any inverse, we also consider the flow in deep channels, effects of individual eddies in the flux of properties, and the differences in circulation that cause the bulk diagnostics of this solution to differ from those in other solutions, as described below.

\section{Heat and freshwater fluxes in the South Atlantic}

In a study of the fluxes on the WOCE A11 section, Saunders and King (1995b, hereinafter SKb) diagnosed a northward heat flux of $0.53 \pm 0.1 \mathrm{PW}$ (Table 1). This heat flux, calculated to represent a climatological mean, was somewhat higher than previous South Atlantic heat flux estimates (typically $\sim 0.3 \mathrm{PW}$ : e.g., Rintoul 1991 and Macdonald 1993). However, these estimates were 


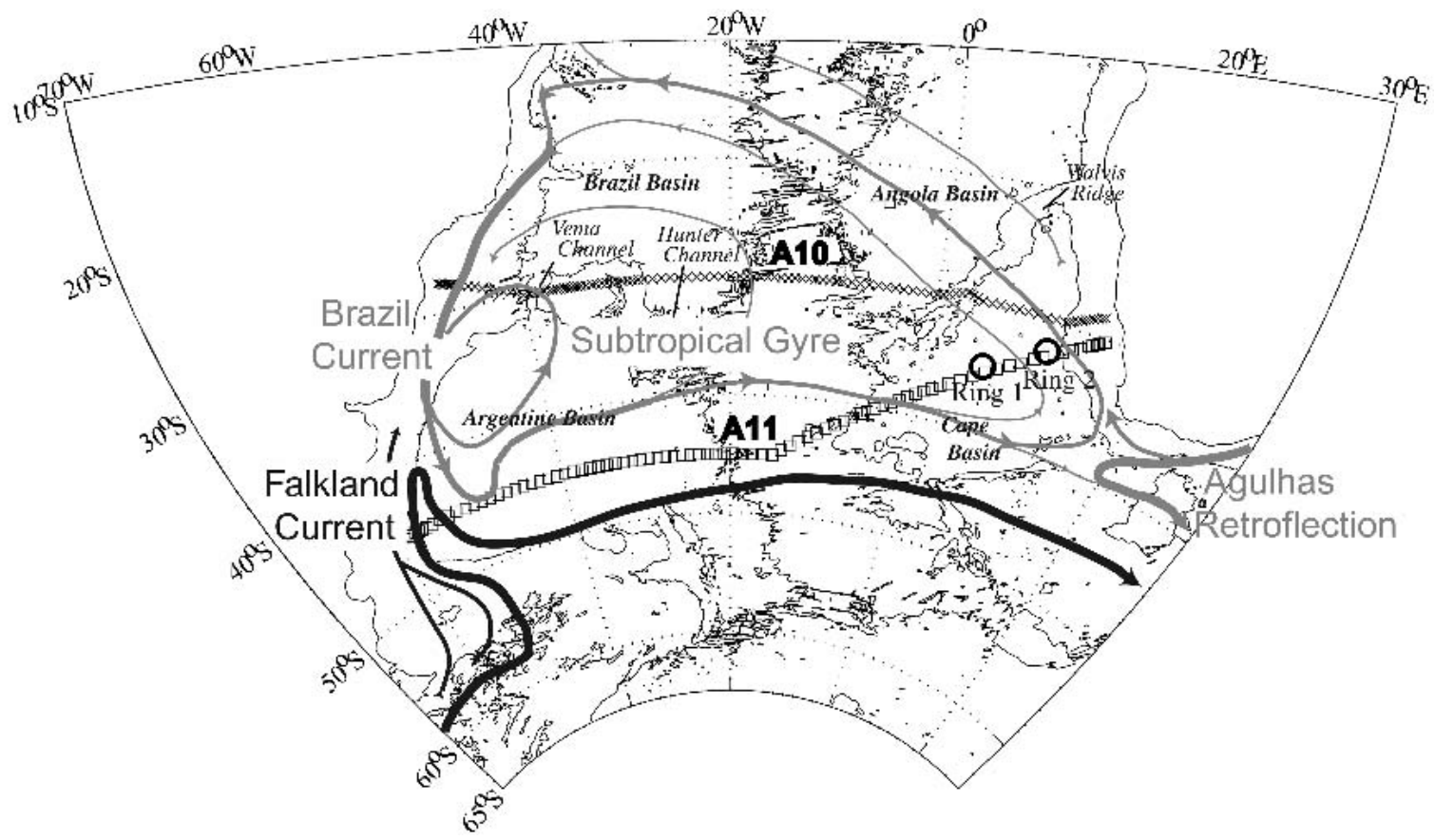

FIG. 1. Positions of A10 and A11 CTD stations. The positions of the two rings sampled on A11 are marked. Surface circulation is based on that of Stramma and England (1999).

made from sections that were up to $15^{\circ}$ of latitude farther north than the A11 section.

Integrated surface flux climatologies suggest uncertainty about the oceanic heat convergence between A11 and A10 in the South Atlantic. The Bunker fields suggest convergence (heat loss to the atmosphere) of $\sim 0.05 \mathrm{PW}$, while the Southampton Oceanography Centre (SOC) climatology (Josey et al. 1999) suggests a divergence (heat gain by the ocean) of 0.2 PW. However, this divergence becomes a 0.1-PW convergence if the SOC climatology is uniformly adjusted to account for its global imbalance of $30 \mathrm{Wm}^{-2}$. This is almost exactly equal to the $29 \mathrm{~W} \mathrm{~m}^{-2}$ adjustment to the heat flux that Grist and Josey (2003) calculated for the re- gion between A10 and A11 when they adjusted the SOC climatology using ocean heat transport constraints including those from this study. Any of these results falls short of the convergence of $\sim 0.2 \mathrm{PW}$ implied by the $\mathrm{SKb}$ result.

The global box inverse study of Ganachaud (1999) derived heat fluxes of $0.66 \pm 0.12 \mathrm{PW}$ and $0.35 \pm 0.15$ PW across A11 and A10, respectively (Table 1). This gives an implied oceanic convergence of $0.31 \pm 0.19$ $\mathrm{PW}$. The magnitude of this convergence is high when compared with the integrated surface flux climatologies. In an inverse analysis of South Atlantic hydrographic sections Holfort and Siedler (2001) calculated northward heat fluxes of $0.37 \pm 0.02 \mathrm{PW}$ and $0.29 \pm$

TABLE 1. Summary of previous estimates of mass $\left(\mathrm{Tg} \mathrm{s}^{-1}\right.$ or $\left.\mathrm{Sv}\right)$, heat (PW), and salt $\left(\mathrm{Gg} \mathrm{s}^{-1}\right.$ or Sv psu) fluxes across A10 and A11 sections (positive fluxes are northward).

\begin{tabular}{|c|c|c|c|c|c|c|}
\hline \multirow[b]{2}{*}{ Source } & \multicolumn{3}{|c|}{ A10 } & \multicolumn{3}{|c|}{ A11 } \\
\hline & $\begin{array}{c}\text { Mass } \\
\left(\mathrm{Tg} \mathrm{s}^{-1} \text { or } \mathrm{Sv}\right)\end{array}$ & Heat (PW) & $\begin{array}{l}\text { Salt } \\
\left(\mathrm{Gg} \mathrm{s}^{-1} \text { or }\right. \\
\text { Sv psu })\end{array}$ & $\begin{array}{c}\text { Mass } \\
\left(\mathrm{Tg} \mathrm{s}^{-1} \text { or } \mathrm{Sv}\right)\end{array}$ & Heat (PW) & $\begin{array}{l}\text { Salt } \\
\left(\mathrm{Gg} \mathrm{s}^{-1} \text { or }\right. \\
\text { Sv psu) }\end{array}$ \\
\hline Saunders and King (1995b) & - & - & - & 0 & $0.53 \pm 0.1$ & $0.8 \pm 5.0$ \\
\hline Ganachaud (1999) & $1 \pm 3$ & $0.35 \pm 0.15$ & - & $1 \pm 3$ & $0.66 \pm 0.12$ & - \\
\hline $\begin{array}{l}\text { Ganachaud and Wunsch (2003) and } \\
\text { A. Ganachaud (2003, personal } \\
\text { communication) }\end{array}$ & 0 & - & $-9 \pm 4 *$ & 0 & & $9 \pm 5^{*}$ \\
\hline Holfort and Siedler (2001) & $-0.53 \pm 0.03$ & $0.29 \pm 0.05$ & $-26.75 \pm 0.77$ & $-0.56 \pm 0.03$ & $0.37 \pm 0.02$ & $-26.37 \pm 0.73$ \\
\hline This study & 0 & $0.22 \pm 0.08$ & $-9.7 \pm 2.9$ & 0 & $0.43 \pm 0.08$ & $-2.9 \pm 2.9$ \\
\hline
\end{tabular}

* These numbers are reported as fluxes of salinity anomaly relative to the section average salinity and as such are equivalent to the zero net mass flux solution. 
0.05 PW across A11 and A10, respectively (Table 1). The magnitude of the oceanic heat convergence that they find is consistent with the integrated surface flux climatologies. However, they describe difficulties when they include the A11 section in their inversion. They ascribe this inconsistency to intense mixing between the A10 and A11 sections at the Brazil-Falklands (Malvinas) confluence and water mass formation at the subtropical and polar fronts, and the failure of their model to accommodate these processes. We allow mixing between layers in this study.

In this study the net northward heat flux on A11 is $0.43 \mathrm{PW}$, smaller than SKb's number of $0.53 \mathrm{PW}$ and Ganachaud's (1999) 0.66 PW. The value of 0.22 PW at A10 is consistent with previous published estimates (Table 1). The solution we present has a convergence of heat across the perimeter of the box, implying a net loss to the atmosphere of $0.21 \mathrm{PW}$, with a formal uncertainty (one standard error) of 0.1 PW. The statistics of the determination are therefore marginal, but a net heat loss to the atmosphere is likely.

In section 5 we will look at the elements of the circulation that change, resulting in the different heat fluxes in ours and other solutions. We will focus on A11 where the different solutions give the most widely varying results (Table 1).

SKb estimated a freshwater flux that was inconsistent with the results of Wijffels et al. (1992). In a global study of freshwater divergence based on the Baumgartner and Reichel (1975) climatology, Wijffels et al. calculated a climatological freshwater loss to the atmosphere of $0.7 \mathrm{~Sv}\left(1 \mathrm{~Sv} \equiv 10^{6} \mathrm{~m}^{3} \mathrm{~s}^{-1}\right)$ over the Atlantic between the Arctic and $35^{\circ} \mathrm{S}$. This implies that the volume flux across A11 should be $\sim 0.7 \mathrm{~Sv}$ less than that through Bering Strait (approximate because A11 is on average south of $35^{\circ} \mathrm{S}$ ) while the salt flux is the same (as salt is conserved). For a Bering Strait volume and salt flux of 0.8 Sv and 26.0 Sv psu (Coachman and Aagaard 1988), then according to SKb, the freshwater flux across A11 would need to be $0.75 \mathrm{~Sv}$ southward to conserve salt (Table 2). This implies a near-zero freshwater divergence over the Atlantic. In this study we intend to combine the A10 and A11 sections to test the conclusions of $\mathrm{SKb}$, as suggested in the last paragraph of that manuscript.

In a comprehensive review of ocean freshwater trans-

TABLE 2. Freshwater fluxes (Sv) across A10 and A11 sections (positive fluxes are northward). These are calculated relative to a Bering Strait throughflow of $0.8 \mathrm{~Sv}$ at an average salinity of 32.5 . Section average salinities are 34.81 on A10 and 34.65 on A11.

\begin{tabular}{lcc}
\hline \hline \multicolumn{1}{c}{ Source } & A10 (Sv) & A11 (Sv) \\
\hline Saunders and King (1995b) & - & $-0.75 \pm 0.1$ \\
Estimated from results of & $-0.5 \pm 0.1$ & $-1.0 \pm 0.2$ \\
$\quad$ Ganachaud and Wunsch (2003) & & \\
$\begin{array}{l}\text { Estimated from results of Holfort } \\
\quad \text { and Siedler (2001) }\end{array}$ & $-0.51 \pm 0.02$ & $-0.55 \pm 0.02$ \\
This study & $-0.5 \pm 0.1$ & $-0.7 \pm 0.1$ \\
\hline
\end{tabular}

port, Wijffels (2001) found that integrated surface flux products gave Atlantic freshwater divergences of between 1.0 and $-0.1 \mathrm{~Sv}$ between Bering Strait and $40^{\circ} \mathrm{S}$, although only 1 of the 11 climatologies shown in Wijffels' Fig. 6.2.7 has a negative divergence. The remaining 10 climatologies all require net freshwater loss by the ocean between Bering Strait and $40^{\circ}-45^{\circ} \mathrm{S}$. The median of the family is about $0.3 \mathrm{~Sv}$ : this is less than that of Baumgartner and Reichel, but not small enough to be consistent with the near-zero divergence of $\mathrm{SKb}$ and Holfort and Siedler (2001). The same calculation for the salt and salinity anomaly fluxes presented by Holfort and Siedler (2001) and Ganachaud and Wunsch (2003) give the freshwater fluxes shown in Table 2. The southward freshwater flux of $0.5 \mathrm{~Sv}$ across A10 derived from the results of Ganachaud and Wunsch (2003) is very close to the fluxes derived from our results and that from Holfort and Siedler (2001). The freshwater flux on A11 $(0.7 \mathrm{~Sv})$ is close to that calculated by SKb $(0.75 \mathrm{~Sv}$; Table 2$)$. This solution suggests a gain of freshwater from the atmosphere over the domain of the box $(0.2 \pm 0.1 \mathrm{~Sv})$. The SOC climatology gives an integrated freshwater flux of $0.01 \mathrm{~Sv}$ out of the ocean between the A10 and A11 sections. This is in comparison with a near-zero freshwater gain in the Holfort and Siedler solution and a large $0.5-\mathrm{Sv}$ gain in the solution of Ganachaud and Wunsch (2003). Thus our results and those of Ganachaud and Wunsch (2003) are consistent with the observation of Wijffels (2001) that several direct estimates give a near-zero freshwater flux over the Atlantic. In section 5 we report that, when we force the A10-A11 system to carry a salt flux consistent with that at the Bering Strait and a near-zero volume flux, we find that it gives an unrealistic circulation.

\section{Data used}

\section{a. Properties on sections}

\section{1) DATA PREPARATION}

Potential temperature, salinity, and silicate sections are shown in Figs. 2 and 3. The silicate data from bottle samples were optimally interpolated (Roemmich 1983) onto the 2-dbar grid of CTD data. Silicate data were interpolated onto each point of the grid using neutral density as the vertical coordinate. A geostrophic velocity profile was calculated for each station pair. The geostrophic velocity in the "bottom triangle" was set to be the same as that at the deepest common level for the station pair. The exception to this formulation was in the Vema Channel on A10, detailed below. Properties were extrapolated into the space between the bottom of a CTD cast (the deeper of the station pair for geostrophic velocity) and the bathymetry beneath that station by reproducing the deepest value.

McDonagh et al. (2002) found that the bottom triangles in the deep Vema Channel were too deep (up to 

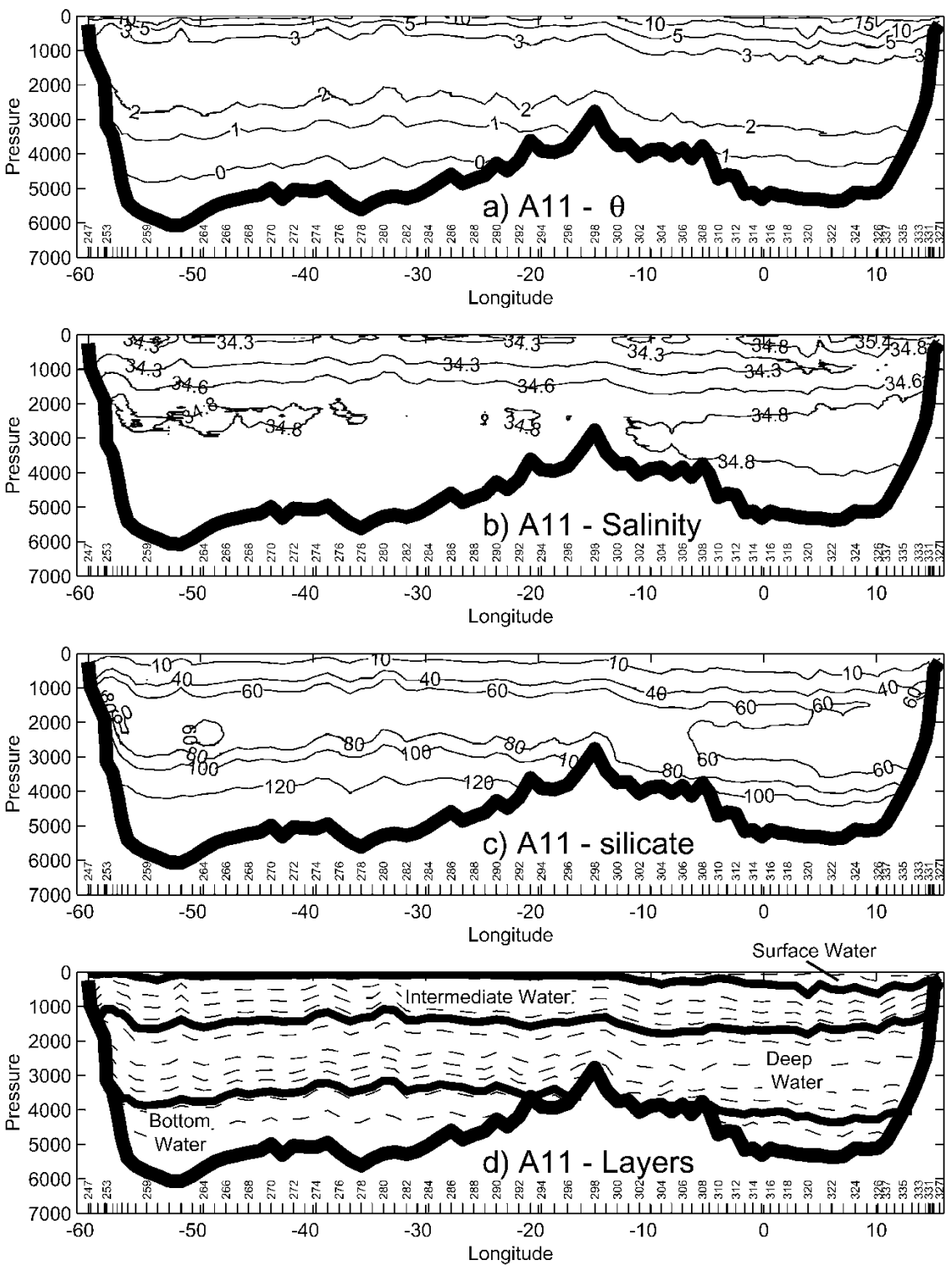

FIG. 2. (a) Potential temperature $\left({ }^{\circ} \mathrm{C}\right)$, (b) salinity on the practical salinity scale, and (c) silicate concentration $\left(\mu \mathrm{mol} \mathrm{kg}{ }^{-1}\right)$ along the A11 section. (d) The positions of the interfaces of the layers used in the inversion in dashed and thick lines. Thick lines indicate the interfaces between the four main water masses. Station positions and numbers are indicated at the bottom of each plot. The unique Discovery station number is obtained by adding a " 12 " prefix to the station numbers reported in these plots.

$950 \mathrm{~m})$ to accurately reproduce the transport of bottom water using the velocity extrapolation scheme described above. The Vema Channel is one of two deep channels that accommodate the northward flow of Antarctic Bottom Water (AABW) at this latitude. Accurately representing the flow through this channel is crucial to determining the overturning circulation. Indeed, Vanicek and Siedler (2002) ascribe unrealistic structure in the bottom-water sublayers in their South Atlantic inverse to be the result of poor resolution of the flow in the Vema Channel on A10. Here we fix the velocity field in the bottom triangles of the two station pairs that sample the deepest part of the Vema Channel (station pairs 10-11 and 11-12) so that the transport of bottom water is comparable to that derived from other higher density sections across the deep Vema Channel. We linearly extrapolate the velocity shear over the $100 \mathrm{~m}$ above the deepest common level for these station pairs. This yields a flux of $3.49 \mathrm{~Sv}$ of water cooler than $2^{\circ} \mathrm{C}$ with a level of no motion on the $2^{\circ} \mathrm{C}$ isotherm. Using similar levels of no motion and water mass definitions the bottom water flow through the deep Vema Channel 

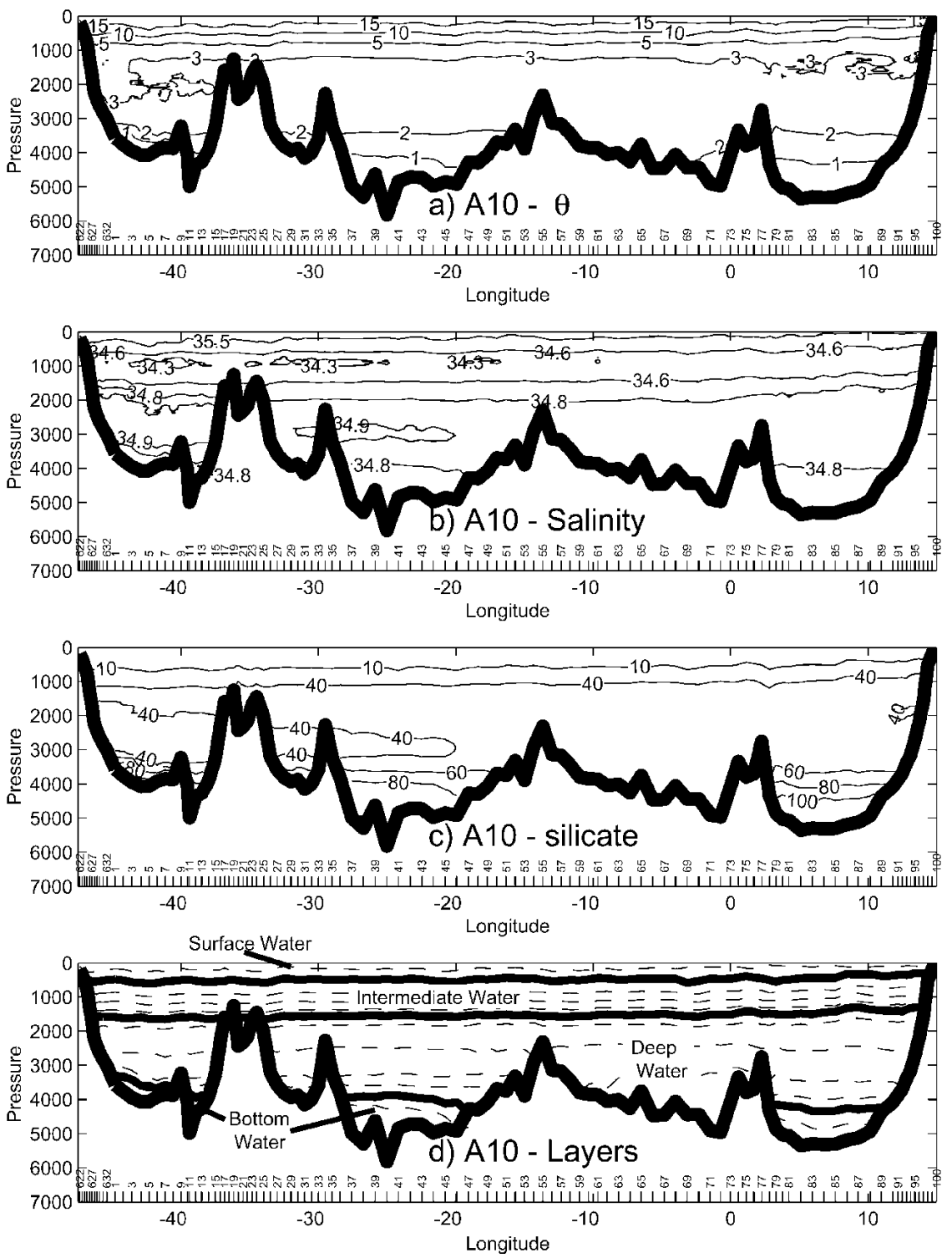

FIG. 3. As in Fig. 2, but for the A10 section.

has been estimated to be between 2.7 and $4.5 \mathrm{~Sv}$ (McDonagh et al. 2002; Hogg et al. 1982; Hogg and Owens 1999).

\section{2) WATER MASSES}

The sections were split into 14 potential density layers (Table 3), including those used by SKb. These layers subdivided the four main water masses. The uppermost of these is surface water, which includes South Atlantic Central Water. Although surface water is present everywhere, it is thickest in the subtropical gyre (STG), that is, everywhere on $\mathrm{A} 10$, east of $\sim 12^{\circ} \mathrm{W}$ on $\mathrm{A} 11$, and in the Brazil-Falklands confluence at approximately $53^{\circ} \mathrm{W}$ on A11. The surface water is the warmest and most saline water mass on the sections. Below the surface water is intermediate water. This is distinguished by the salinity minimum of Antarctic Intermediate Water but also includes Upper Circumpolar Deep Water. Intermediate waters enter the box from south of the A11 section. Beneath the intermediate waters, North Atlantic Deep Water is evidenced by a salinity maximum. NADW enters the box from the north. Below the deep water the salinity decreases and the coldest water on the sections is found in the bottom-water layer. This layer includes Weddell Sea Deep Water formed to the south of the box and Lower Circumpolar Deep Water, which also enters the box from the south. The bottom water has the highest silicate content of the sections. Bottom water is present everywhere other than over 
TABLE 3. Layer descriptions.

\begin{tabular}{ccl}
\hline \hline Layer & Layer limits & \\
\hline 1 & $\sigma_{0}<26.2$ & Surface water \\
2 & $26.2<\sigma_{0}<26.8$ & \\
3 & $26.8<\sigma_{0}<27.2$ & Intermediate water \\
4 & $27.2<\sigma_{0}, \sigma_{1}<32.0$ & \\
5 & $32.0<\sigma_{1}<32.16$ & \\
6 & $32.16<\sigma_{1}<32.26$ & \\
7 & $32.26<\sigma_{1}<32.36$ & Deep water \\
8 & $36.36<\sigma_{1}, \sigma_{2}<37.0$ & \\
9 & $37.0<\sigma_{2}, \sigma_{3}<41.5$ & \\
10 & $41.5<\sigma_{3}<41.54$ & \\
11 & $41.54<\sigma_{3}<41.58$ & \\
12 & $41.58<\sigma_{3}<41.6$ & Bottom water \\
13 & $41.6<\sigma_{3}<41.66$ & \\
14 & $41.66<\sigma_{3}$ & \\
\hline
\end{tabular}

the Mid-Atlantic Ridge on A11. On A10 the northward progression of bottom water into the Angola Basin is limited by the Walvis Ridge.

\section{b. Agulhas rings}

Two Agulhas rings (Ring 1 and Ring 2) were sampled at the eastern end of A11 (Fig. 1, Saunders and King 1995a; McDonagh et al. 1999). The presence of the rings on the section raises two issues. The first is the contribution of rings (transient features) to the heat flux across A11 in addition to the "mean" flux calculated from the geostrophic velocity field and the temperature field. SKb quantified the ring contribution to the heat flux to be $0.05 \mathrm{PW}$ (their Table 6). The second consideration is the inclusion and interpretation of transient features on a section. The main signature of the velocity field around the rings is one of rotation. This portion of the flow is mass compensating. Assuming that the properties are symmetrically distributed about the center of the ring, there will also be no net effect on the property flux. However, the rings are also advected in the geostrophic flow field. Using ring radii (from the station spacing) of 56 and $104 \mathrm{~km}$ and temperature excesses over the surroundings of $2.9^{\circ}$ and $2.3^{\circ} \mathrm{C}$ for Ring 1 and Ring 2, respectively, gives a combined heat flux of $0.02 \mathrm{PW}$ above $700 \mathrm{~m}$ for each $1 \mathrm{~cm}$ $\mathrm{s}^{-1}$ that the rings are advected. Therefore, it follows that the presence of the rings on the section and their interpretation as part of the mean field will, given an increase in the intensity of the gyre in which they are embedded, be associated with an increase in the heat flux, and vice versa. This is an increase in heat flux that would not be present had the rings not been sampled, all other things being equal.

This calculation shows that the presence of the rings potentially has a significant effect on one of the key results that we hope to diagnose. In order to properly assess the effect of including the rings, we duplicate our experiments using a dataset that excludes the information from within the rings. We deleted the CTD data from the three stations that sampled the rings (12320, 12325 , and 12326). We then simulated density profiles at these stations by linear interpolation of the ambient density field. The local temperature and salinity properties were then interpolated on density onto the simulated profiles. The bottle data were simulated as described in section 2 with the information from the three stations within the rings excluded from the optimal interpolation.

For the system described in this paper, the solution that includes the rings had a heat flux across A11 that was $0.08 \pm 0.14 \mathrm{PW}$ larger than the solution with the rings excluded. This was close enough to the predicted (0.05 PW) contribution of the rings to the heat flux across A11 that the solution with the rings on the section was retained. This is the only solution presented henceforth.

As some Agulhas Rings remain intact north of $30^{\circ} \mathrm{S}$ (Byrne et al. 1995), they will also contribute to the heat flux across A10. Byrne et al. (1995) used satellite altimetry data to trace the path of Agulhas rings across the South Atlantic. Using their results, we estimate that half of the rings that cross A11 remain intact north of the A10 section at $30^{\circ} \mathrm{S}$. Therefore the rings contribute $0.05 \mathrm{PW}$ to the heat flux across A11 and 0.025 PW to the heat flux across A10. The difference between the heat fluxes across A11 and A10 (0.025 PW or $\left.6 \mathrm{~Sv}^{\circ} \mathrm{C}\right)$ is equivalent to the amount of heat injected into the box by the rings as they are dispersed by mixing into the ambient water. Examining the structure of the more easterly of the two rings (deemed a "typical" Agulhas ring by McDonagh et al. 1999) shows that the vast majority of this heat flux occurs in the surface layer. As the uncertainty on the surface layer is large $\left( \pm 24 \mathrm{~Sv}{ }^{\circ} \mathrm{C}\right)$ compared with this input of heat, we do not explicitly include this source of heat for the surface layer in the box.

\section{c. Ekman}

As described in the introduction, we use an average or climatological representation of Ekman velocity. To create this we use the Hellerman and Rosenstein (1983) winds. This gives a northward volume flux of $5.6 \mathrm{~Sv}$ across A11 and $-0.4 \mathrm{~Sv}$ across A10. We allow for a $50 \%$ uncertainty in the A11 value and a $1 \mathrm{~Sv}$ uncertainty in the A10 value. Although we use the mean Ekman velocity field, we convolve this with the property fields measured on A11. The largest seasonal effect is likely to be on temperature. SKb consider this and conclude that using the January temperature field will overestimate the annual average heat flux by no more than 0.05 PW on A11. This effect is equivalent to a mass-compensated heat convergence of $12 \mathrm{~Sv}{ }^{\circ} \mathrm{C}$. The effect is split between the top two layers. The uncertainties in layers 1 and 2 are \pm 24 and $\pm 12 \mathrm{~Sv}{ }^{\circ} \mathrm{C}$, respectively. We consider these uncertainties to be large 
TABLE 4. Adjustments to a single level of no motion to construct the initial geostrophic velocity field.

\begin{tabular}{cccl}
\hline \hline & $\begin{array}{c}\text { Station } \\
\text { pairs }\end{array}$ & $\begin{array}{c}\text { Velocity } \\
\left(\mathrm{m} \mathrm{s}^{-1}\right)\end{array}$ & \\
(positive northward) & \multicolumn{1}{c}{ Comments } \\
\hline A10 & $1-5$ & -0.2333 & $\begin{array}{l}\text { Brazil Current }=-25 \mathrm{~Sv} \\
\text { Brazil Current recirculation } \\
=7.5 \mathrm{~Sv}\end{array}$ \\
& $6-11$ & 0.0170 & $\begin{array}{l}\text { Zero net mass flux } \\
\end{array}$ \\
& All & -0.000966 & Falklands Current $=45 \mathrm{~Sv}$ \\
A11 & $1-4$ & 0.1966 & Zero net mass flux \\
& All & -0.000788 & \\
\hline
\end{tabular}

enough to absorb the effects of the seasonal bias in the Ekman temperature flux. The effect will be negligible on A10 because of the small magnitude of the Ekman volume flux there.

\section{d. Referencing the geostrophic velocity field- Initial state}

The inverse procedure diagnoses variables (including reference level velocities). In order to choose a solution in this underdetermined system assumptions must be made. We chose the solution that is closest to our initial state (minimum weighted sum of squares of the solution variables). Therefore we require our initial state to contain as much prior knowledge of the circulation as possible. Initially we reference each section to a zero velocity surface near the NADW-AABW interface $\left(\sigma_{3}=41.55\right)$. Where this interface does not exist the velocity was referenced to zero at the deepest common level. We then included more information in the initial velocity field by adding a single velocity offset to the station pairs that spanned a feature (for example a boundary current) to adjust the volume flux to a chosen value. These modifications are given in Table 4. A sepa- rate velocity value was then added to each section to compensate for net mass flux through the section (Table 4). The fluxes associated with this initial state are included in Table 5.

\section{Method used}

\section{a. The inverse method}

The problem is represented by an equation,

$$
\mathbf{A x}+\boldsymbol{\varepsilon}=\mathbf{b},
$$

where vector $\mathbf{x}$ is $n \times 1$ ( $n$ rows, 1 column) and contains the unknowns. The $(m \times n)$ matrix $\mathbf{A}$ contains information about the geometry of the system and has one row for each constraint, and the $(m \times 1)$ vector $\mathbf{b}$ contains information about values to which the system is to be constrained. The $(m \times 1)$ vector $\boldsymbol{\varepsilon}$ is an error vector. For example, for a single constraint of no mass flux across the A10 section, the $n$ columns of $\mathbf{A}$ would contain station pair areas for A10 in the columns corresponding to the A10 reference level velocities and be zero elsewhere. Vector $\mathbf{b}$ would be of length unity and contain the negative net mass flux across A10 in the initial field. Then adding the solution field to the initial field will provide a final flux of zero. For any more than one station pair this simple example is underdetermined, and even with all of our constraints (described below) the full system is underdetermined (i.e., there are more unknowns than equations: $n>m$ ). We solve the system $\mathbf{A x}=\mathbf{b}$ using a truncated singular value decomposition (SVD). We employed the software suite "DOBOX" (Morgan 1995), modified locally to incorporate some extra features.

Truncating the SVD is important. If the full rank solution were used, all the equations would be satisfied exactly. However, we know that the equations contain

TABLE 5. Constraints additional to property conservation in layers. Uncertainties are equivalent to one standard deviation. Transports (Sv) are positive northward. For reference, the shipboard station numbers corresponding to the western and eastern limits of the constraints are listed. Station pair numbers are west to east along the sections. In our inversion, A11 (91 stations) has station pairs 1-90; A10 (111 stations) has station pairs 91-200. All mass constraints are in Sverdrups $\left(10^{6} \mathrm{~m}^{3} \mathrm{~s}^{-1}\right)$.

\begin{tabular}{lccccc}
\hline \hline & & Shipboard station & & & \\
& Station pairs & Nos. & Initial (Sv) & Constraint (Sv) & Solution (Sv) \\
\hline & & & A11 & & \\
Falkland Current & $1: 4$ & $12247: 12251$ & 45.0 & $45 \pm 10$ & $42.7 \pm 6.5$ \\
Eastern boundary current & $86: 90$ & $12332: 12327$ & 1.7 & $-5 \pm 2$ & $-5.1 \pm 1.9$ \\
Cape Basin AABW & $58: 84$ & $12304: 12333$ & -0.2 & $0 \pm 0.5$ & $-0.1 \pm 0.5$ \\
Argentine Basin AABW & $7: 50$ & $12253: 12297$ & -7.0 & $6 \pm 1$ & $5.6 \pm 1$ \\
Net mass transport & $1: 90$ & $12247: 12327$ & 0.0 & $0 \pm 4$ & $0.9 \pm 3.2$ \\
& & & A10 & $-25 \pm 10$ & $-17.3 \pm 3.3$ \\
Brazil Current & $91: 95$ & $622: 627$ & -25.0 & $7.5 \pm 5$ & $7.4 \pm 4.9$ \\
Brazil Current recirculation & $96: 101$ & $627: 1$ & 7.5 & $2 \pm 1$ & $2.2 \pm 1$ \\
Vema Channel AABW & $91: 120$ & $622: 20$ & 0.4 & $0 \pm 0.5$ & $3.2 \pm 1$ \\
Brazil Basin AABW & $128: 149$ & $27: 49$ & 0.3 & $0.1 \pm 0.5$ \\
Cape Basin AABW & $170: 200$ & $69: 100$ & 0.0 & 0.1 & $0.8 \pm 3.2$ \\
Net mass transport & $91: 200$ & $12332: 12327,95: 100$ & 0.0 & 0.5 & $0.0 \pm 0.5$ \\
Eastern ends of sections & $86: 90,196: 200$ & & & 0.5 \\
\hline
\end{tabular}


errors, the size of which can be estimated. To satisfy the equations exactly using the full rank solution would introduce noise and detail for which there is no justification. Furthermore, there is an inherent redundancy in the equations. For example, the equation for conservation of total salt is not independent of the equation for conservation of volume. To a certain extent this effect can be removed by use of layer anomalies for temperature, salt, and other tracers.

We chose to truncate the SVD at a rank (number of eigenvector/eigenvalue sets) where the residuals for each equation (the difference between $\mathbf{A x}$ and $\mathbf{b}$ ) are less than twice the uncertainty for that equation (given in the constraint column of Table 5). This is the simplest solution vector that satisfies each constraint to within $2 \varepsilon_{i}$. For the A10 net flux constraint this would mean a residual of less than $8 \mathrm{~Sv}$ (Table 5). Increasing the rank reduces the size of the residuals but adds noise rather than insight.

\section{b. Unknowns}

We solve for 90 reference level velocities on A11 and 110 reference level velocities on A10. The initial geostrophic field is set up to best reflect our knowledge of the circulation (described above). We describe perturbations to this as the addition of a reference level velocity and so, by definition, the reference level velocities are initially zero.

McIntosh and Rintoul (1997) found that in order to obtain an accurate set of reference level velocities in their analysis of GCM output it was very important to include some form of interlayer exchange. Here, mixing is accommodated between layers in the box by the inclusion of an interlayer velocity $(w)$ and a diffusive-type mixing $\left(k_{z}\right)$. The diffusive mixing coefficient acted on the average of the vertical gradient of a property over $50 \mathrm{~m}$ centered on the layer-layer interface. The gradient was estimated from data on the perimeter of the box. The vertical velocity acts uniformly over the area of the box, or less if a layer intersects the sea surface or seabed. Therefore we also solved for $13 \mathrm{w}$ and $13 k_{z}$ variables to allow mixing at the interfaces of each of the 14 layers. The $w$ and $k_{z}$ variables were initialized to be zero.

Interaction with the atmosphere is included via a freshwater flux and a heat flux at the ocean surface. These two variables are constant over the whole box and act on the layers that outcrop (layers 1 and 2). The proportion of the area over which a layer outcrops in the box is assumed to be equal to the fraction of the section lengths over which it outcrops. Layer 1 has $81 \%$ of the outcrop area, equal to $6.7 \times 10^{12} \mathrm{~m}^{2}$. Layer 2 has $19 \%$, equal to $1.6 \times 10^{12} \mathrm{~m}^{2}$. The freshwater and heat fluxes were initialized to be $7 \mathrm{~mm} \mathrm{month}{ }^{-1}(0.01 \mathrm{~Sv})$ and $0 \mathrm{~W} \mathrm{~m}^{-2}$. The freshwater flux (positive out of the ocean surface) represents an annual mean from the SOC climatology (Josey et al. 1999). The $30 \mathrm{~W} \mathrm{~m}^{-2}$ global bias in the surface heat fluxes of SOC climatol- ogy meant that we rejected the $-20 \mathrm{~W} \mathrm{~m}^{-2}$ climatology mean for the box and initialized the surface heat flux at $0 \mathrm{~W} \mathrm{~m}^{-2}$.

The final two variables are corrections to the Ekman flux on A10 and A11. They represent a single offset (i.e., assumed to be a uniform volume flux per kilometer of track) to the Ekman volume flux across the whole section. These were initially set to zero.

\section{c. Constraints}

We applied constraints to conserve volume, potential temperature, and salinity in each layer within the box. We also constrained the top-to-bottom convergence of volume, potential temperature, salinity, and silicate within the box. The exact formulation of the variables that were constrained is described below. The uncertainties on each of these constraints (the formulation of which is described in the next section on row weighting) are shown in Table 6 .

Rather than conserving a property (e.g., salinity) in a layer we conserved a layer anomaly (e.g., salinity minus layer-average salinity). The importance of using anomalies is discussed by McDougall (1991). These layer anomaly variables are used for potential temperature, salinity, and silicate. Constructing constraints from anomaly variables in this way improves the condition of the system by reducing the dependence of the property equations on the volume (mass) equations. Top-to-bottom property conservation was also imposed. Top-to-bottom property equations were constructed for an anomaly from the average concentration in the layer for which the product of mass uncertainty and property standard deviation is largest. This is the surface layer for salinity and potential temperature, but is middepth for silicate. This is designed to decouple the anticipated large mass variance in the surface layers from large values of the property anomaly concentration, which would lead to erroneous sources and sinks of that property. This scheme for top-to-bottom conservation is described by Ganachaud (1999).

In addition to these 46 constraints (14 layers and topto-bottom, three variables plus top-to-bottom in silicate; Table 6) are 12 constraints based on our prior knowledge of the circulation (see Table 5). The five A11 additional constraints are the same as those used by SKb. On A10 we constrain the Brazil Current and its recirculation based on the work of Zemba (1991). The southward transport of the Brazil Current that we use $(25 \pm 10 \mathrm{~Sv})$ is consistent with the transport of $22.4 \pm$ $11.3 \mathrm{~Sv}$ that Müller et al. (1998) deduced from currentmeter records. A detailed study of the Vema Channel has shown a southward recirculation of $1.5 \mathrm{~Sv}$ of bottom water on the eastern flank of the Vema Channel (McDonagh et al. 2002). This recirculation is to the east of the deepest part of the Vema Channel (which has been the focus of most previous studies) and contains a lighter, shallower form of the bottom water. Based on this we conserve the Vema Channel throughflow to be 
TABLE 6. Uncertainties for layer and top-to-bottom constraints. Prior uncertainties are formulated as described in the text. Posterior uncertainties (in parentheses) are calculated following the method and assumptions of McIntosh and Rintoul (1997).

\begin{tabular}{lcccc}
\hline \hline & Layer & Mass $(\mathrm{Sv})$ & $\begin{array}{c}\text { Potential } \\
\text { temperature }\left(\mathrm{Sv}^{\circ} \mathrm{C}\right)\end{array}$ & $\begin{array}{c}\text { Silicate } \\
\left(\mathrm{Sv} \mu \mathrm{mol} \mathrm{kg}^{-1}\right)\end{array}$ \\
\hline Surface water & 1 & $4(2.8)$ & $24.2(21.2)$ & $4.32(3.05)$ \\
Intermediate water & 2 & $4(3.4)$ & $11.9(11.3)$ & $2.89(1.38)$ \\
& 3 & $2(1.9)$ & $4.1(3.9)$ & $0.51(0.40)$ \\
& 4 & $2(1.8)$ & $1.6(1.6)$ & $0.22(0.21)$ \\
Deep water & 5 & $2(1.8)$ & $1.0(0.8)$ & $0.13(0.13)$ \\
& 6 & $1(1.8)$ & $0.6(0.5)$ & $0.08(0.08)$ \\
& 7 & $1(1.0)$ & $0.3(0.3)$ & $0.05(0.05)$ \\
Bottom water & 8 & $1(1.0)$ & $0.3(0.3)$ & $0.07(0.05)$ \\
& 10 & $1(1.0)$ & $0.4(0.4)$ & $0.07(0.07)$ \\
& 11 & $1(1.0)$ & $0.3(0.4)$ & $0.05(0.05)$ \\
& 12 & $1(0.9)$ & $0.2(0.2)$ & $0.04(0.04)$ \\
& 13 & $1(0.9)$ & $0.4(0.4)$ & $0.04(0.04)$ \\
\end{tabular}

$2 \pm 1 \mathrm{~Sv}$ on A10. We constrain the bottom-water transport through the Brazil Basin east of the Rio Grande Rise on $\mathrm{A} 10$ to be $3 \pm 1 \mathrm{~Sv}$. This is based on the bottom water transport through the Hunter Channel of $2.9 \pm$ $1.24 \mathrm{~Sv}$ calculated by Zenk et al. (1999). As on A11, where there are no bottom water escape routes to the north, we conserve the net bottom-water flow in the Cape Basin on A10 to be $0 \pm 0.5 \mathrm{~Sv}$. We use the same net volume flux uncertainty on $\mathrm{A} 10$ as on A11 ( $0 \pm 4$ $\mathrm{Sv})$. In addition to this we constrain the eastern ends of the two sections (within $200 \mathrm{~km}$ of one another) to have $0 \pm 0.5 \mathrm{~Sv}$ divergence between the sections.

\section{d. Row/column weighting}

\section{1) Row WeIGHTING}

This involves premultiplying the matrix $\mathbf{A}$ by $\mathbf{W}_{r}$ (where $\mathbf{W}_{r}^{2}$ is the prior equation error covariance matrix); $\mathbf{W}_{r}$ is square $(m \times m)$ with one row for each equation. We assume all errors are uncorrelated and so $\mathbf{W}_{r}$ is diagonal. When weighted, each row of $\mathbf{A}$ is effectively divided by the product of the mass uncertainty and the property standard deviation for that layer. This standard deviation is doubled to account for variations in the baroclinic field (Ganachaud 1999). For the topto-bottom equations the maximum layer product for that property is used as a weight. This comes from the surface layers for salinity and potential temperature, but is middepth for silicate. The silicate weight is doubled again to account for uncertainties in the silicate budget and the interpolation scheme.

\section{2) Column weighting}

Here $\mathbf{A}$ is postmultiplied by a square diagonal matrix $(n \times n)$ with the same number of rows as variables, $\mathbf{W}_{c}$; $\mathbf{W}_{c}^{2}$ is the prior solution error covariance matrix. The elements of $\mathbf{W}_{c}$ are the combination of several contributions. We construct $\mathbf{W}_{c}$ as the product of a "relativesize" component $\mathbf{W}_{\text {crel }}$ and a "magnitude" component $\mathbf{W}_{c \text { mag. }}$ Leaving out the error term, the constrained system becomes

$$
\left(\mathbf{A} \mathbf{W}_{c \text { rel }}\right)\left(\mathbf{W}_{c \text { rel }}^{-1} \mathbf{x}\right)=\mathbf{b} .
$$

To account for the different size and units of the different types of unknown variables, we require the elements of $\mathbf{W}_{c \text { rel }}^{-\mathbf{1}}$ to be $1 / \sigma_{i}$ so that each variable is scaled by an estimate of its expected size (Table 7). We now have $\mathbf{A}^{\prime} \mathbf{x}^{\prime}=\mathbf{b}$ and, for example, $\mathbf{A}_{11}^{\prime}=\mathbf{A}_{11} \sigma_{1}$. The system of equations can be further written as

$$
\left(\mathbf{A}^{\prime} \mathbf{W}_{c \mathrm{mag}}\right) \mathbf{W}_{c \mathrm{mag}}{ }^{-1} \mathbf{x}^{\prime}=\mathbf{b} \text {. }
$$

Here the elements of $\mathbf{W}_{c \text { mag }}$ are chosen to account for the size of the elements in the $\mathbf{A}^{\prime}$ matrix. If the elements of $\mathbf{A}^{\prime}$ are station pair areas, and if $\mathbf{W}_{c \text { rel }}$ was the identity matrix, the elements of $\mathbf{W}_{c \text { mag }}$ would be chosen to be $1 / \sqrt{(\text { area })}$. This would ensure that a single constraint adjusting an entire section to a volume flux of zero would result in a uniform velocity offset rather than one that depended on the water depth or station spacing. Since $\mathbf{A}^{\prime}{ }_{11}=\mathbf{A}_{11} \sigma_{1}$, we choose $\mathbf{W}_{c \text { mag } i}=1 / \sqrt{\left(\operatorname{area}_{i} \times \sigma_{i}\right)}$. Hence the elements of $\mathbf{W}_{\mathrm{c}}$ would be $\sigma_{i} / \sqrt{\left(\text { area }_{i} \times \sigma_{i}\right)}$ $=\sqrt{\left(\sigma_{i} / \text { area }_{i}\right)}$.

There is one further component of $\mathbf{W}_{c}$. In the case

TABLE 7. Standard deviation of variables for column weights.

\begin{tabular}{ll}
\hline \hline \multicolumn{1}{c}{ Variable } & \multicolumn{1}{c}{ Std dev } \\
\hline Reference level velocity & $10^{-2} \mathrm{~m} \mathrm{~s}^{-1}$ \\
$w$ (interface velocity) & $10^{-8} \mathrm{~m} \mathrm{~s}^{-1}$ or $0.1 \mathrm{~Sv}$ \\
$k_{z}$ (effective diffusivity coefficient) & $10^{-4} \mathrm{~m}^{2} \mathrm{~s}^{-1}$ \\
$E-P$ (surface freshwater flux) & $10^{-8} \mathrm{~m} \mathrm{~s}^{-1}$ or $0.1 \mathrm{~Sv}$ \\
$H$ (surface heat flux) & $12 \mathrm{~W} \mathrm{~m}$ or $^{-2} 0.1 \mathrm{PW}$ \\
Correction to Ekman volume flux (A11) & $2.8 \mathrm{~Sv}$ \\
Correction to Ekman volume flux (A10) & $1 \mathrm{~Sv}$ \\
\hline
\end{tabular}


where the only unknowns are reference-level velocities, and elements of $\mathbf{A}$ are station pair areas, the choice of $\mathbf{W}_{c \text { mag }}$ is straightforward. We consider first the case of Ekman flux, which contributes to the upper two layers only. The formulation of $\mathbf{W}_{c}$ described so far has the Ekman flux columns weighted for the upper 60 dbar times the section track length, and the reference-level velocities weighted for the full water column area. If we consider just the surface-layer conservation equations, it is apparent that the relative weight between the Ekman columns and the reference level velocity columns should be based on the station pair surface layer areas instead of station pair total water column areas. The reference level velocity column weights should therefore be larger relative to the Ekman column weights, and we include a further factor in the Ekman column weights of $f_{i}=\sqrt{(60 / 4420)} \sim 0.1$.

Similarly, the contribution to fluxes from interfacial terms contribute mainly in conservation equations for a single layer in which the station pair areas are calculated from that layer and not from the full water depth. Since we have 14 density layers, we reduce the column weight for these terms by a factor $f_{i}=\sqrt{(1 / 14)} \sim 0.3$. For the reference level velocity columns, $f_{i}=1$.

\section{e. Uncertainties}

The posterior covariance was calculated following the method and assumptions of McIntosh and Rintoul (1997). The main assumption is that the ensemble mean, or initial estimate, of the solution is zero. This is consistent with setting up an initial state that we believe to be as close to the solution as possible.

\section{Features of the solution circulation}

\section{a. Surface and intermediate waters}

On A10, the surface and intermediate layers have a southward flow between South America and $42^{\circ} \mathrm{W}$, with a northward return over the remainder of the section (Fig. 4a). This is typical of an intense western boundary current and return flow over the rest of the subtropical gyre. The flow is disrupted by southward flow on the western side of the Brazil Basin. Boebel et al. (1997), who deduced flow patterns from float tracks, observed disruption of the intermediate water flow upstream of the Rio Grande Rise. This solution indicates that the enhanced northward flow that they observed immediately to the east of the Rio Grande Rise is preceded (in the sense of being upstream) by a southward excursion of the flow in a region where there were no float data.

On A11, the major feature near South America is the Falkland Current and return circulation and its confluence with the Brazil Current (Fig. 4b). Nothing new is noted here. The extension of the Falkland Current into the sub-Antarctic front (SAF) accumulates as northward flow across the west part of the section. When the section turns northward at $15^{\circ} \mathrm{W}$, the accumulation of these layers returns toward zero and crosses zero net flow at $12^{\circ} \mathrm{W}$ (Fig. $4 \mathrm{~b}$ ).

Examination of the temperature-salinity (T-S) properties shows that the position of the subtropical front (STF) - that is to say, the boundary of the subtropical gyre (STG) on A11-is between stations $12301\left(12^{\circ} \mathrm{W}\right)$ and $12302\left(11^{\circ} \mathrm{W}\right)$ for the surface layer and between stations $12299\left(14^{\circ} \mathrm{W}\right)$ and $12300\left(13^{\circ} \mathrm{W}\right)$ for the intermediate layer. East of station $12301\left(12^{\circ} \mathrm{W}\right)$ we see mesoscale variability superposed on an anticyclonic circulation. The section cuts the edge of the STG, and the strength of circulation sampled by the section is of the order of $8 \mathrm{~Sv}$ in each of the surface and intermediate layers. In addition to the anticyclonic circulation there is a northward flow of surface water at the eastern end of the section. The net northward flow is $10.1 \mathrm{~Sv}$ east of station pair $12301-12302\left(11.5^{\circ} \mathrm{W}\right)$ in the surface and $-1.9 \mathrm{~Sv}$ east of station pair $12300-12301\left(13.5^{\circ} \mathrm{W}\right)$ in the intermediate layer. We will return to discussion of these net flows later.

\section{b. Deep water}

At A10, the deep western boundary current is $20 \mathrm{~Sv}$, which reduces to $10 \mathrm{~Sv}$ at the latitude of A11 (Fig. 4). The remainder escapes to the east. This is consistent with the results of Vanicek and Siedler (2002) who find $10 \pm 5 \mathrm{~Sv}$ of NADW moving eastward across a $25^{\circ} \mathrm{W}$ section between the A10 and A11 sections. There is a pronounced southward flow west of the Mid-Atlantic Ridge (MAR) and over the Walvis Ridge; there is no significant deep boundary current at the eastern end of A10. This pattern of southward flow over the Walvis Ridge at about $30^{\circ} \mathrm{S}$ and the absence of a deep southward current on the African boundary is consistent with the schematic of Stramma and England (1999, their Fig. 5). It is also consistent with the fact that the deep-water salinity maximum was higher over Walvis Ridge (34.879) than at the eastern boundary (34.874) on A10.

At A11, the cumulative flow in the rest of the Argentine Basin (east of the deep western boundary current) is northward and, as for the intermediate layer, is dominated by the SAF. West of the MAR, the SAF appears to take an excursion to the north so that between stations $12292\left(21.7^{\circ} \mathrm{W}\right)$ and $12299\left(14^{\circ} \mathrm{W}\right)$ there is a total northward flow of $30 \mathrm{~Sv}$. Heywood and King (2003) report that at $35^{\circ} \mathrm{W}$ the SAF transports $57 \mathrm{~Sv}$ eastward across $150 \mathrm{~km}$ of north-south track. Therefore a northward excursion of the front of $80 \mathrm{~km}$ would mean that A11 would sample about one-half of the SAF transport and would account for the 30-Sv transport observed between 12292 and 12299. This equatorward excursion is consistent with the tendency to reduce the planetary vorticity as the current moves over the shallower topography of the MAR.

In the Cape Basin, the deep flow on A11 is part of a cyclonic gyre, with magnitude about $15 \mathrm{~Sv}$. The southward flow at the eastern side of the cyclonic gyre is 
a) A10 - layer transports

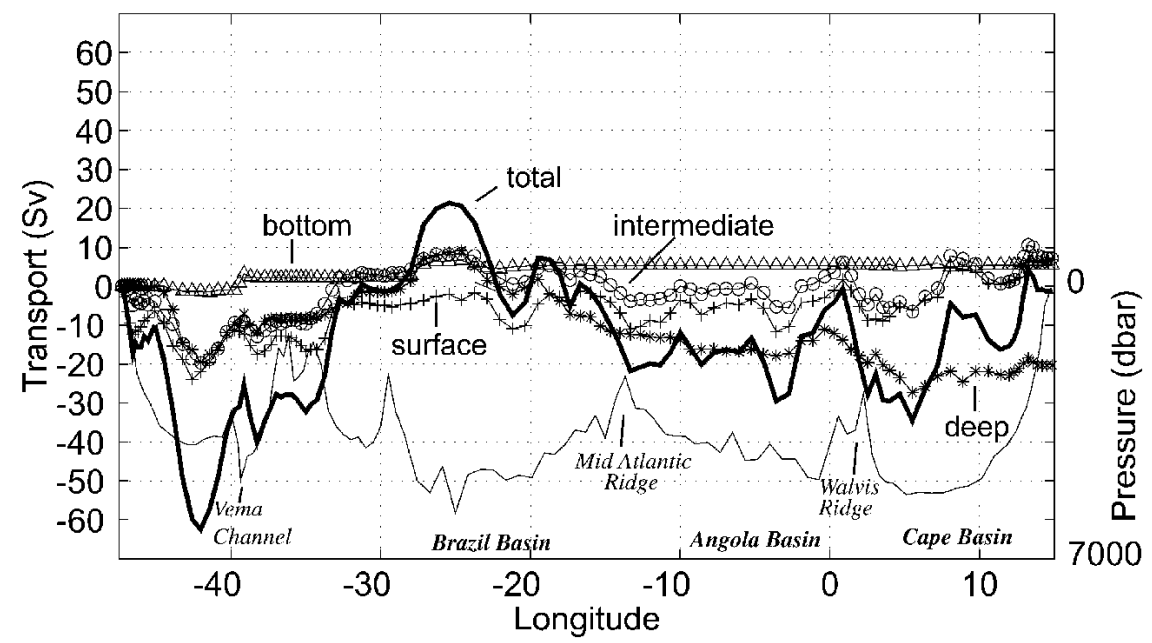

b) A11 - layer transports

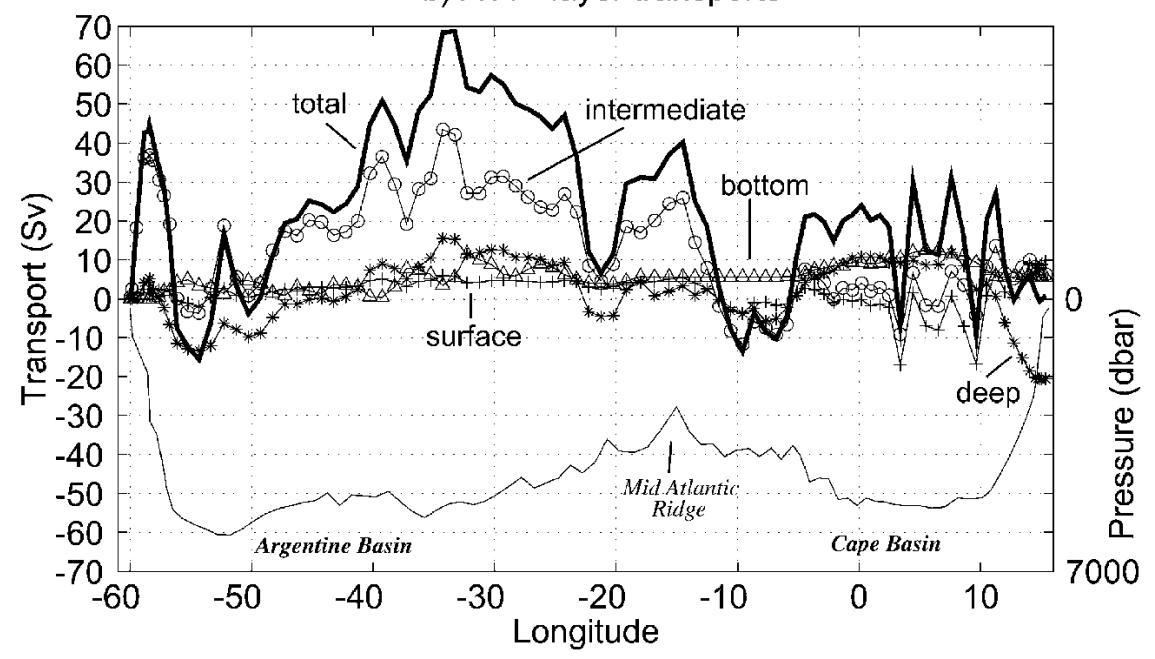

FIG. 4. Transport (Sv, positive northward) cumulated from the western end of the section for (a) A10 and (b) A11. Transports of surface (+), intermediate (o), deep (*), and bottom $(\Delta)$ water are shown as well as the total transport (thick line). The thin line shows the pressure of the bathymetry in each plot.

augmented by a southward deep boundary current that is also of magnitude $15 \mathrm{~Sv}$. The net southward flow of deep water is $21.0 \mathrm{~Sv}$.

\section{c. Bottom water}

The net flows of bottom water are largely determined by the constraints applied. On A11, there is a boundary current at the foot of the slope at the western end of the section and a number of local circulations. The cyclonic circulation of bottom water in the Cape Basin is $8 \mathrm{~Sv}$.

\section{d. The overturning and gyre circulation}

The overturning circulation is summarized in Table 8 . The overall strength, as measured by the southward flow of deep water [primarily NADW-see section
$3 \mathrm{a}(2)]$, is $20 \pm 2 \mathrm{~Sv}$ at $\mathrm{A} 10$ and $21 \pm 2 \mathrm{~Sv}$ at A11. These fluxes are insignificantly different from the solution of SKb who had 21.7 Sv at A11 and Holfort and Siedler's 22.7 Sv at A10 (G. Siedler 2000, personal communication) if we assume their error bars are similar to ours. Ganachaud (1999) derived NADW fluxes of $23 \pm 3 \mathrm{~Sv}$ (A10) and $18 \pm 4 \mathrm{~Sv}$ (A11). Not only do the studies have no significant difference in the overturning, there is also an insignificant divergence of the NADW in the box. This result is reconfirmed when we consider the interpretation of the interlayer fluxes.

More interesting and significant are differences in the horizontal circulation between this solution and $\mathrm{SKb}$ (Fig. 5). The most striking difference is in the circulation in the Cape Basin. The SKb solution was anticyclonic in both intermediate and deep layers. This solu- 


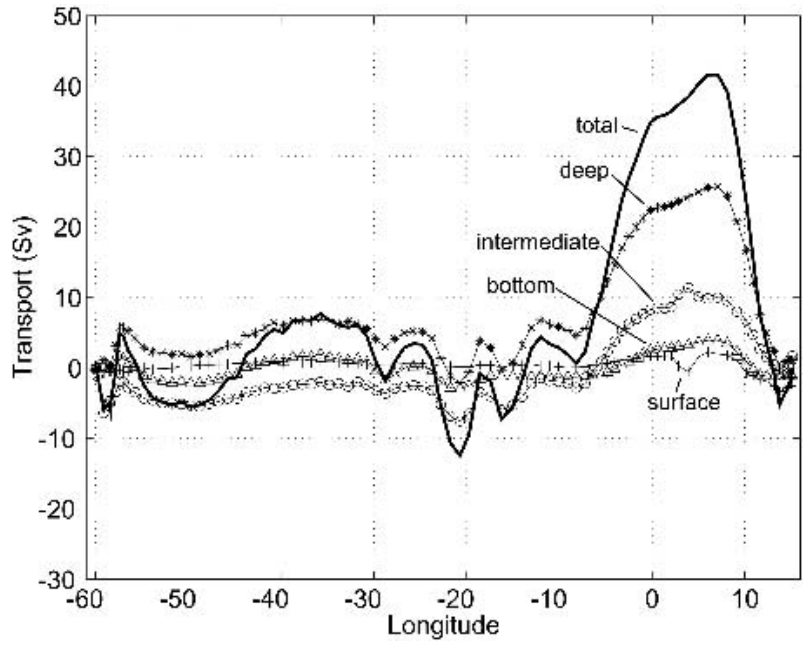

FIG. 5. Difference in cumulative transport (Sv, positive northward) between this solution and that of Saunders and King (1995b) (this solution minus theirs). Transport differences of surface $(+)$, intermediate (o), deep (*), and bottom $(\Delta)$ water are shown as well as the total transport (thick line).

tion adds a cyclonic component so that the intermediate anticyclonic circulation is weaker but still anticyclonic. The sense of the solution in the deep water is reversed and is now cyclonic as described earlier. It is moving in the same sense as the bottom water and the deep boundary current. We note that the initial reference state for the inversion has a northward heat flux of 0.93 PW (and anticyclonic flow in the deep water). The solution of $\mathrm{SKb}(0.53 \mathrm{PW})$ departs from the initial state as required by its constraints. It would appear from the cumulative transport diagrams shown by Ganachaud that his circulation in the Cape Basin differs from the

TABLE 8. Solution fluxes on the sections corrected to zero net mass flux except the net freshwater flux that is calculated relative to a Bering Strait throughflow of $0.8 \mathrm{~Sv}$ at an average salinity of 32.5 .

\begin{tabular}{lcc}
\hline \hline & A10 & A11 \\
\hline Layer transports (Sv) & 7.1 & \\
$\quad$ Surface & 7.3 & 9.7 \\
Intermediate & -19.9 & -21.0 \\
Deep & 5.5 & 5.3 \\
Bottom & & \\
Heat (PW) & -0.03 & 0.21 \\
$\quad$ Ekman & 0.55 & 0.17 \\
Overturning & -0.31 & 0.05 \\
$\quad$ Gyre & $0.22 \pm 0.08$ & $0.43 \pm 0.08$ \\
Total heat & -9.7 & -2.9 \\
Total salt (Sv psu) & & \\
Section average & 4.35 & 2.58 \\
$\quad$ Potential temperature $\left({ }^{\circ} \mathrm{C}\right)$ & 34.81 & 34.65 \\
$\quad$ Salinity & -0.5 & -0.7 \\
Net freshwater flux $(\mathrm{Sv})$ & & \\
\hline
\end{tabular}

present solution in the same sense as SKb but with greater magnitude. That is to say, his circulation has an even greater anticyclonic component, which combines with the temperature field to provide greater northward heat flux (0.66 PW). The extra constraints in this solution result in further departure from the initial state with a cyclonic component that results in less northward heat flux.

The distribution between Ekman, overturning, and gyre contributions is shown in Table 8. Comparison with the distribution published by $\mathrm{SKb}$ shows that the combined overturning and Ekman heat flux (0.38 PW) is slightly stronger than $\mathrm{SKb}(0.35)$ but that the significant change is in the gyre element: $0.05 \mathrm{PW}$ as compared with an SKb 0.18 PW. The change is due to the added cyclonic component combined with the alongtrack temperature gradient in the Cape Basin, and so there is less transport of warm water northward.

\section{e. Freshwater fluxes}

All of the studies shown in Table 2 give a significant southward freshwater flux at A11 between 0.55 and 1.0 Sv. We attempted to force our solution to a salt flux of 26.0 Sv psu southwards and a small or zero net volume flux. There is not enough horizontal salinity variation for the salt flux constraint to be met by reasonable adjustment of the gyre strengths. Therefore the solution can only accommodate such a constraint by combining the vertical gradient with a modified overturning, and the result was excessive overturning of the order of $35 \mathrm{~Sv}$. The heat transport in that solution is not excessive: it is achieved by an exchange of fresher intermediate and saltier deep water across the section, but we reject it as unreasonable.

\section{f. Interpretation of $w$ and $k_{z}$}

The interlayer volume fluxes implied by the solution vertical velocities are typically of order $0.5 \mathrm{~Sv}$. However, the actual magnitudes are of limited significance because they are no greater than the layer residuals and one-half (or less) of the posterior uncertainty in the layer residuals (Table 6). The solution values of $k_{z}$ are all insignificantly different from zero, apart from the diffusive flux between layers 1 and 2 that has a value of $1.02 \times 10^{-4} \mathrm{~m}^{2} \mathrm{~s}^{-1}$. This value may be a reflection of higher mixing near the surface, but may also be the result of an oversimplified partitioning of the surface fluxes between the outcropping (top two) layers. When the interfacial fluxes are omitted, the system responds by significantly altering elements of the system that primarily affect the top two layers by reducing the northward Ekman flux across A11 by $10 \%$, reducing the Falklands Current and the Brazil Current by $20 \%$, and reducing the surface heat flux by $90 \%$. Therefore we conclude that, although mixing is insignificant in this system away from the surface, the interfacial fluxes are important in maintaining balance in the surface layers of this system. 


\section{Discussion}

\section{a. Cold versus warm water path}

The net northward flux of upper-level waters in the overturning circulation at A11 is split between $9.7 \mathrm{~Sv}$ of surface waters and 6.0 Sv of intermediate waters, suggesting a role for both warm and cold water paths for the return of deep water to the Atlantic. As noted in section $5 \mathrm{a}$, we find that the net northward flux of intermediate water is entirely from west of the subtropical gyre $\left(12^{\circ} \mathrm{W}\right)$, that is, the cold water path. In the subtropical gyre the accumulation of intermediate water is slightly negative, implying no role for the warm water path in the return of intermediate water to the Atlantic. This result does not preclude the flux of intermediate water from the Indian Ocean to the Atlantic Ocean such as that implied from the observations (McDonagh et al. 1999 and Gordon et al. 1992) but it does imply that the conversion of deep to intermediate water has occurred upstream of the Indian Ocean.

\section{b. What other measurements would enable the uncertainties to be reduced?}

We estimate that the uncertainty in the reported heat fluxes is $0.08 \mathrm{PW}$ on each section. This is based on the assumptions set out in the description of the inverse calculations. We believe this uncertainty to be realistic, even if larger than we had hoped when the study was begun. The uncertainty is dominated by uncertainty in the location and temperature of the flow near the surface.

Part of the uncertainty comes from formal uncertainty in the baroclinic structure: the uncertainty of the estimate of the mean from a single realization of the section is proportional to the standard deviation of the measurements. In order to significantly reduce the standard error of the estimate of the mean, a large number of occupations of the section (e.g., 5 or 10) would be required. Therefore this may not be the most fruitful way to proceed. Rather, we note that the horizontal fluxes are strongly influenced by the following.

1) The horizontal circulation in the Cape Basin, which could be determined by direct observations (e.g., with subsurface floats), is a factor.

2) The horizontal distribution along the sections of the cross-track velocity is also a factor. Redistribution of the reference velocity, combined with along-track variations of properties, provides a significant source of possible error. This contributes to the final uncertainty through a large standard deviation of a property (e.g., temperature anomaly relative to layer average). If the box could be subdivided by a north-south section, so that the box comprises a number of smaller boxes, and if the subsections were of rather more uniform properties, the uncertainty in property flux across each subsection would be reduced.
3) The silica distribution varies in a strikingly different manner from the salinity and temperature. Improved knowledge of the silica budget (reduced uncertainty in the strength of the sources and sink) would enable more use to be made of constraints on silica fluxes and divergences.

\section{Summary}

We have undertaken a box inverse of the WOCE South Atlantic A10 $\left(30^{\circ} \mathrm{S}\right)$ and A11 $\left(\sim 45^{\circ} \mathrm{S}\right)$ sections in which we have attempted to take into account all available prior knowledge about local circulations and fluxes. We conclude that previous estimates of northwards heat flux at A11 by Saunders and King (1995b) and Ganachaud (1999) were too high. We prefer 0.43 PW (Fig. 6), closer to the value reported by Holfort and Siedler (2001). However, we find a southward freshwater flux of $0.7 \mathrm{~Sv}$, consistent with previous direct estimates and still inconsistent with the net Atlantic evaporation required by all but one of the climatologies reviewed by Wijffels (2001). Our results suggest a net loss of heat to the atmosphere between the sections and a small gain of freshwater (Fig. 6).

The difference in the A11 heat flux between our solution and that of Saunders and King (1995b) and Ganachaud (1999) is primarily dictated by the strength of the subtropical anticyclonic gyre that cuts across at the eastern end of the A11 section. The strongest anticyclonic gyre (Ganachaud 1999) gives the highest heat flux (0.66 PW). This gyre is then relatively weaker in the Saunders and King (1995b) solution, which has a lower heat flux of $0.53 \mathrm{PW}$, and then weaker again in this solution, which has an associated heat flux of 0.43 PW. Ours is the only one of these three solutions in

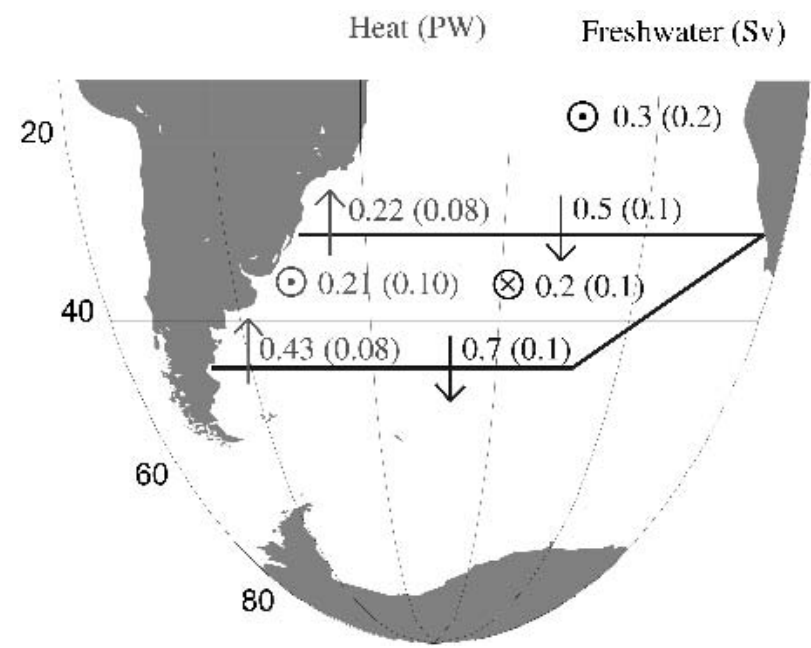

FIG. 6. Heat transport (PW) and freshwater transport (Sv) through the box and the implied freshwater divergence (Sv) in the Atlantic to the north of the box. Uncertainties are given in brackets. 
which the anticyclonic gyre is sufficiently weak to allow the deep and bottom waters to circulate cyclonically around the Cape Basin. The deep cyclonic circulation is consistent with Stramma and England's (1999) observations of cyclonic bottom-water circulation and a southward-flowing NADW at the eastern edge of the Cape Basin. That means that this circulation, and an associated heat flux of $0.43 \mathrm{PW}$, is more credible than the previous studies discussed here.

Acknowledgments. We are grateful to two anonymous referees and the editor for suggestions on how to modify the first draft of this paper. Alex Ganachaud and Gerold Siedler kindly provided statistics from their analyses not included in their publications. We also thank the originators of the DOBOX code made available from CSIRO, Hobart.

\section{REFERENCES}

Baumgartner, A., and E. Reichel, 1975: The World Water Balance: Mean Annual Global, Continental and Maritime Precipitation. Elsevier, $179 \mathrm{pp}$.

Boebel, O., C. Schmid, and W. Zenk, 1997: Flow and recirculation of Antarctic Intermediate Water across the Rio Grande Rise. J. Geophys. Res., 102, 20 967-20 986.

Bryden, H., and S. Imawaki, 2001: Ocean heat transport. Ocean Circulation and Climate, G. Siedler, J. Church, and J. Gould, Eds., International Geophysics Series, Vol. 77, Academic Press, 455-474.

Byrne, D. A., A. L. Gordon, and W. F. Haxby, 1995: Agulhas eddies: A synoptic view using Geosat ERM data. J. Phys. Oceanogr., 25, 902-917.

Coachman, L. K., and K. Aagaard, 1988: Transports through Bering Strait: Annual and interannual variability. J. Geophys. Res., 93, 15 535-15 539.

Ganachaud, A. S., 1999: Large scale oceanic circulation and fluxes of freshwater, heat, nutrients and oxygen. Ph.D. thesis, Massachusetts Institute of Technology/Woods Hole Oceanographic Institution Joint Program, 267 pp.

— , and C. Wunsch, 2003: Large-scale ocean heat and freshwater transports during the World Ocean Circulation Experiment. J. Climate, 16, 696-705.

Gordon, A. L., R. F. Weiss, W. M. Smethie, and M. J. Warner, 1992: Thermocline and intermediate water communication between the South Atlantic and Indian Ocean. J. Geophys. Res., 97, 7223-7240.

Grist, J. P., and S. A. Josey, 2003: Inverse analysis adjustment of the SOC air-sea flux climatology using ocean heat transport constraints. J. Climate, 16, 3274-3295.

Hellerman, S., and M. Rosenstein, 1983: Normal monthly wind stress over the World Ocean with error estimates. J. Phys. Oceanogr., 13, 1093-1104.

Heywood, K. J., and B. A. King, 2003: Water masses and baroclinic transports in the South Atlantic and Southern Oceans. J. Mar. Res., 60, 639-676.

Hogg, N. G., and W. B. Owens, 1999: Direct measurement of the deep circulation within the Brazil Basin. Deep-Sea Res., 46, 335-353.

—, P. Biscaye, W. Gardner, and W. J. Schmitz Jr., 1982: On the transport and modification of Antarctic Bottom Water in the Vema Channel. J. Mar. Res., 40, 231-263.

Holfort, J., and G. Siedler, 2001: The meridional oceanic transports of heat and nutrients in the South Atlantic. J. Phys. Oceanogr., 31, 5-29.

Josey, S. A., E. C. Kent, and P. K. Taylor, 1999: New insights into the ocean heat budget closure problem from analysis of the SOC air-sea flux climatology. J. Climate, 12, 2856-2880.

Macdonald, A. M., 1993: Property fluxes at $30^{\circ} \mathrm{S}$ and their implications for the Pacific-Indian throughflow and the global heat budget. J. Geophys. Res., 98, 6851-6868.

McDonagh, E. L., K. J. Heywood, and M. P. Meredith, 1999: On the structure, paths and fluxes associated with Agulhas rings. J. Geophys. Res., 104, 21 007-21 020.

— M. Mrhan, and K. J. Heywood, 2002: On the circulation of bottom water in the region of the Vema Channel. Deep-Sea Res., 49, 1119-1139.

McDougall, T. J., 1991: Parameterizing mixing in inverse models. Dynamics of Oceanic Internal Gravity Waves, 'Aha Huliko'a Hawaiian Winter Workshop, P. Muller and D. Henderson, Eds., Honolulu, HI, University of Hawaii at Manoa, 355-386.

McIntosh, P. C., and S. R. Rintoul, 1997: Do box inverse models work? J. Phys. Oceanogr., 27, 291-308.

Morgan, P. P., 1995: Box inverse modelling with DOBOX 4.2. CSIRO Marine Laboratories Rep. 225, 26 pp.

Müller, T. J., Y. Ikeda, N. Zangenberg, and L. V. Nonato, 1998: Direct measurements of western boundary currents off Brazil between $20^{\circ} \mathrm{S}$ and $28^{\circ} \mathrm{S}$. J. Geophys. Res., 103, 5429-5437.

Rintoul, S. R., 1991: South Atlantic interbasin exchange. J. Geophys. Res., 96, 2675-2692.

Roemmich, D., 1983: Optimal estimation of hydrographic station data and derived fields. J. Phys. Oceanogr., 13, 1544-1549.

Saunders, P. M., and B. A. King, 1995a: Bottom currents derived from a shipborne ADCP on WOCE cruise A11 in the South Atlantic. J. Phys. Oceanogr., 25, 329-347.

- and - 1995b: Oceanic fluxes on the WOCE A11 section. J. Phys. Oceanogr., 25, 1942-1958.

Stramma, L., and M. England, 1999: On the water masses and mean circulation of the South Atlantic Ocean. J. Geophys. Res., 104, 20 863-20 883.

Vanicek, M., and G. Siedler, 2002: Zonal fluxes in the deep-water layers of the western South Atlantic. J. Phys. Oceanogr., 32, 2205-2235.

Wijffels, S. E., 2001: Ocean transport of freshwater. Ocean Circulation and Climate, G. Siedler, J. Church, and J. Gould, Eds., International Geophysics Series, Vol. 77, Academic Press, $475-488$.

- R. W. Schmidt, H. L. Bryden, and A. Stigebrandt, 1992: Transport of freshwater by the oceans. J. Phys. Oceanogr., 24, 1666-1679.

Wunsch, C., 1996: The Ocean Circulation Inverse Problem. Cambridge University Press, $442 \mathrm{pp}$.

Zemba, J. C., 1991: The structure and transport of the Brazil Current between $27^{\circ}$ and $36^{\circ}$ S. Ph.D. thesis, Massachusetts Institute of Technology/Woods Hole Oceanographic Institution Joint Program, 160 pp.

Zenk, W., G. Siedler, B. Lenz, and N. G. Hogg, 1999: Antarctic Bottom Water flow through the Hunter Channel. J. Phys. Oceanogr., 29, 2785-2801. 